\title{
Influence of Nature and History of Science Courses on Value Perceptions of Elementary Science Teacher Candidates in Conceptual Dimension in Turkey
}

\author{
Hilal Aktamış*, Emrah Hiğde \\ Department of Science Education, Adnan Menderes University, Turkey \\ *Corresponding Author: hilalaktamis@gmail.com
}

\section{ABSTRACT}

This study aimed to determine the changes in understanding about the nature of science (NOS) and conceptual values of 28 elementary science teacher candidates who engaged in the instruction of the nature and history of science (NHOS). A values scale was used to determine the values of science teacher candidates in six areas of the conceptual dimension: Theoretical, economic, esthetic, politic, social, and religious. An open-ended questionnaire in conjunction with individual interviews was used to assess participants' pre- and post-instruction NOS views. Semi-structured interviews were conducted with six science teacher candidates who were selected from the different value levels: Low, medium, and high according to the results of the value scale. In the light of results of this study, the science teacher candidates who were engaged in the NHOS instruction received the highest score from the theoretical value dimension and the lowest score from the religious value dimension. Therefore, it can be suggested that NHOS teaching influenced the value perceptions of elementary science teacher candidates. For this reason, science teacher candidates' value perception should be considered during the NHOS instruction planning and the teaching of science. Recommendations based on this study include explicitly addressing the NOS aspects in science education courses and history and NOS teaching courses to enhance science teacher candidates' views about specific NOS aspects.

KEY WORDS: nature of science; science teacher candidates; elementary education; values

\section{INTRODUCTION}

$\mathbf{V}$ alues and science are intertwined. Therefore, it is impossible to keep values distinct from science (Allchin, 1998). According to Allchin (1998), the interrelation of science and values is expressed as (a) particularly epistemic values that guide scientific studies, (b) the scientific enterprise is always embedded in some particular culture and values enter science through its individual practitioners, whether consciously or unconsciously, and (c) values stemming from science as products and processes. Besides this, the influence of culture cannot be ignored in science education. During the science education process, students encounter subdisciplines of science, compare them with their own worldviews, accept some of them, and reject some of them. In science classes, the teacher and teacher candidates reflect their own values to lecturing, decisionmaking, and evidence evaluation processes (Ratcliffe, 2012). Levinson and Turner (2001) expressed in their study that value orientations of teachers influenced their interpretation of the syllabus and adaptation of the pedagogical approaches.

In the National and International Science Programs, the effects of the value orientations of students on their understanding of the main concepts of science are on the rise (National Research Council, 2012; Ratcliffe, 2012; Milli Eğitim
Bakanlığ1 [MEB], 2017). Through reform movements in science education in Turkey, steps have been taken to bring up students as science literates from the beginning of the $3^{\text {rd }}$ grade. It has been stipulated within the framework of the Sciences Education Program that an individual, who is scientifically literate, understands the nature of science (NOS) and scientific knowledge, basic science concepts, principles, and theories, uses scientific process skills in problem-solving process, is informed of science, technology, and society topics, understands the interaction between them, possesses scientific attitudes and values, and also, is aware of the values, social structure, and beliefs belonging to the culture that the individual lives in MEB, 2017. For these reasons, studying the relationship of science and values is regarded as important in science education.

\section{NOS, Scientific Literacy}

NOS is a multidisciplinary domain incorporating the social sciences such as philosophy, sociology, and history of science (NHOS). Considering investigations in cognitive sciences such as psychology and the NOS involves how science works, how scientists work as a social group, and how society interacts with scientific endeavors directly or indirectly (McComas et al., 1998). While Lederman (2003) highlighted that it was difficult to make a general definition for the NOS, Akerson 
and Abd-El-Khalick (2005) listed the basic characteristics of the NOS as follows:

- Scientific knowledge is reliable but may change over time.

- There is no single scientific method. There are multiple ways of making science.

- Imagination and creativity have an important role in the generation of scientific knowledge.

- Although there is a relationship between theory and laws, these types of scientific knowledge are different.

- Although there is a relationship between observation and inference, these two processes are different.

- Scientific knowledge is subjective and theory based.

- Scientific knowledge is influenced by the sociocultural environment and it is created.

When the above-listed characteristics of the NOS are examined, it is seen that subjective, social, and cultural values may influence science.

Teachers' views on the NOS influence the students' ways of understanding and engaging with science. Hence, teachers' own understanding of as well as how they explain the NOS is important. In addition, teachers make science more accessible to students by including more philosophy, history, and sociology in their science teaching (Lederman et al., 2013; Solomon et al., 1992).

\section{Values}

Values are accepted as the key structures in the process of socialization. Therefore, they take part as an important variable in religious, cultural, politic, educational, and familial studies. Values are formed according to biological and physiological needs of individuals. More importantly, values have long been associated with attitudes and personalities of people (Braithwaite and Scott, 1991).

Aavik and Allik (2002) stated that values were related to concepts and beliefs and desired outcomes and behaviors that were effective in determination of a behavior and evaluation of an event. Scheler (1913-1916/1973) categorized values into three areas: Personal, vital, and conceptual (factual). Personal values comprise the values such as good, bad, respect, love, and hate by which a human shapes him or herself. Vital values are qualitative values such as strong, ill, weak, hearty, exhausted, and sturdy. The values such as being useful, economic, esthetic, and culturally fit are included in the conceptual values.

In this context, the NOS and conceptual values overlap. For Allport (1960; 1961 as cited in Robinson et al., 2013), values are the beliefs guiding the lifestyle preferred by the individual. It can be suggested that values are the criteria emerging in thoughts, behaviors, attitudes, and products of the individuals. The conceptual values focused on in this study are based on the ones used in Spranger's study "Types of Men" (Allport et al., 1960a) used to explain personalities: Theoretical, economic, esthetic, politic, social, and religious.

Allport et al. (1960a) described the subdimensions in classification, as follows: (1) Theoretical values: The basic tendency of the individual is discovering the reality/fact. (2) Economical values: They are interested in what is useful in qualitative terms, and if the knowledge they will use is not applicable, they do not care about that knowledge. (3) Esthetical value: Esthetical value deals with diversity, whereas theoretical value deals with the identity of the experiences. (4) Social values: The main goal is achieving real friendship and contributing to the happiness of others.

(5) Politic values: Individuals who possess this value care about only power. (6) Religious values: The most important value for an individual with the religious aspect is "unity." An individual of this type conducts research for understanding the universe as a whole and devotes himself to understand this wholeness. The examination of values is a method for understanding individuals, their cultures, and the organizations in which they live. At the cognitive level, values are the key concept in our understanding beliefs, attitudes, behaviors of the individuals, and what is desirable by the individual; at the cultural level, understanding value systems of different cultural groups is important in understanding characteristics of that culture (Roy, 2003). In this context, the investigation of values of the individuals with respect to sciences in this study may help us in understanding characteristics of the culture as well.

According to Stein (1985), social approval is important in the emergence of the values and also role models and impersonation are important in learning the values. While the individual takes his/her parents as a role model in childhood, he/ she proceeds with taking his/her circle of friends and teachers as role models. Therefore, teachers play a critical role in the formation of values. Social roles comprise identity styles such as professional, sexual, social, and personal. Education is a process and values are transferred to the next generation in this process. Therefore, it is important to investigate the values of teacher candidates, and how the awareness of NOS and NHOS influences these values (Sar1, 2005).

Science incorporates rich epistemic values and the cultural values in practice such as: Space science, the human genome initiative, dissection of subatomic matter through large particular accelerators, or even a better understanding of AIDS. The value of the scientific knowledge supported scientifically is through the context of the value of other social projects. In conclusion, scientific knowledge and new technologies may bring new ethical or social problems on the base of the previous values. For example, medical technologies may require us to take into consideration our other values before accepting a solution for a potentially better life and health (Allchin, 1999). In this context, decisions as to what is better in science include social, political, and ethical values.

For Allchin (1999), exclusion of ethical values from science education made it difficult to understand the NOS accurately as well as a deeper understanding of science, values, and objectivity. Hence, the inclusion of the values in science education and discussion of the values should be obligatory (Sadler et al., 2006). Sadler et al. (2006) believed that discussable sociocultural topics were important features of 
science education, ethics and values were part of the discussion of the sociocultural topics, and these topics should have a place in the classroom environment. In this context, teachers should have a vision about values and ethics in science education. To realize this, science teachers should prepare their students to think critically on these topics, evaluate the evidence, and discuss the ethical issues. Education of nature and NHOS allow discussion of scientific topics in a historical context.

Moreover, Allchin (1998) stated that scientific discoveries could not be kept distinct from values such as religion or culture and that introduction of these values into science would help the development of science. Importantly, for this study, the beliefs, values, and experiences possessed by the individual are conveyed in the classroom environment and they shape their teaching (Muğaloğlu and Bayram, 2010). For these reasons, this study aimed to determine the development in value perceptions of the teacher candidates receiving nature and NHOS education. For this purpose, answers were sought for the following questions:

1. How are the conceptual values of science teacher candidates differentiated in the dimension of conceptual values (theoretical, economic, esthetic, social, politic, and religious values)?

2. How have the values of the science teacher candidates changed in the dimension of conceptualization during the lecture of the NOS?

\section{METHODS}

\section{Participants}

A total of 28 science teacher candidates undertaking a course about the NOS voluntarily agreed to participate in this study. Participants studied at a public university in the Aydın Province of Turkey. The course consisted of $3 \mathrm{~h}$ a week for 10 weeks totaling $30 \mathrm{~h}$. Of the participants, 13 were females and 15 males. From among the participants, semi-structured interviews were conducted with two teacher candidates at each level of the value perception including low, medium, and high (6 in total) before and after their education on the nature and NHOS. All names are pseudonyms.

\section{Conducting the Application}

It is possible to change perceptions of teachers, teacher candidates, and students regarding the NOS (Abd-El-Khalick and Lederman, 2000). The approaches were applied to develop the concepts about the NOS possessed by the students. In this study, teacher candidates were assigned one of two NOS teaching approaches either (i) direct and reflective or (ii) historical approaches for the semester.

i. Direct and reflective approach argues that the goal of developing views of the students on the NOS is required to be planned rather than being a side effect of secondary product.

ii. Historical approach claims that teaching the NHOS may strengthen the views possessed by the students about the NOS.
The course was divided into time periods (such as ancient times, the middle ages, and the Renaissance). Using case studies between the $15^{\text {th }}$ and $20^{\text {th }}$ century, the objective of the course was to highlight the rational, psychological, and social characteristics that have typified the meaning and methods of the natural sciences; it focused on the interaction of scientific ideas within their social and cultural contexts. The students, divided into groups, conducted research related to the time periods. The student groups presented their research during the semester. Each researcher told a story about their time period and discussed their story in class. They make conclusions about the methods and processes of acquiring scientific knowledge. Students performed a drama about Galileo and his life in scientific discovery context after they read a history about the life of Galileo. Educational games were played for the purpose of reinforcement (for example, Chinese whispers and whowhose-where-when-what). For three course hours, students watched a science film about some key figures in science, including Einstein. After watching the film, students talked about scientists and challenges confronted them during the time period of their scientific discovery. Within the class, the process used by scientists to acquire knowledge was discussed along with their understanding of associated subjects, the sociology, and philosophy of science.

\section{Data Collection}

The values scale developed by Allport et al. (1960b) was used in the study to determine the values of the teacher candidates in the dimension of conceptualization after its reliability was analyzed. Semi-structured interviews used an interview protocol pre-test and post-test that was prepared by drawing on the literature. The interviews were conducted with six volunteer teacher candidates $(n=6)$ selected from each level: High, medium, and low. The teacher candidates were grouped according to the scores they received from the values scale. The interviews lasted from 30 to $50 \mathrm{~min}$. All interviews were audio-recorded and transcribed for analysis.

\section{Data Collection Instruments}

Allport values scale: Values Scale measure the theoretical, economic, esthetic, social, political, and religious values and the relative prominence of six value types in a person's life (Allport et al., 1960a). They (1960a) suggested that each person's values are a combination of these six types: Theoretical, economic, esthetic, social, political, and religious.

This scale was composed of two parts. The first 30 items were couplets (Part One: 60 scores), and the final 15 items were quartets (Part Two: 60 scores). In Part 1, the respondent rated 30 items regarding activities, preferences, and desired outcomes by allocating points between two alternatives, each of which represented one of Spranger's values. A strong preference for one value over the other was indicated by allocating 3 points to the first and 0 points to the second, while a slight preference was indicated by allocating 2 points to the first and 1 point to the second. Part 2 was similar, but the respondent ranked four possible alternatives (representing 
four of the Spranger values) by assigning a score of 4, 3, 2, or 1 to each alternative. There were 120 response options in all, 20 of which refer to each of the six values. A score of 40 on each would indicated equal preference for the six values. Each individual received a total score of 240 points, based on answers to questions describing a number of familiar situations. Consequently, the value scale measured the relative strength of each value orientation. The theoretical average for each value is 40 (240 points apportioned among six values), but individual profiles often demonstrate unique value patterns.

The scale was adapted into Turkish by Cansever et al. (cited in Ardac et al., 1994). In the Turkish adaptation of the scale, several expressions found in the original form were changed so that they were a better fit to the Turkish culture. For instance, the terms involving religion were altered. Such as, the word "Kuran" ("Koran") was used instead of "Incil" ("Bible"). Similarly, names of known Turkish people were used such as "Kanuni Sultan Süleyman" ("Suleiman, the Magnificent") instead of "Julius Caesar" (Muğaloğlu and Bayram, 2010).

In this study, the validity and reliability study conducted by Koruklu and Aktamış (2012) was taken into consideration. For language validity of the scale, it was read by experts, and the unclear words were corrected by the researchers. The reliability coefficient of the scale was calculated with Spearman-Brown formula using split-half reliability method. The results obtained for each subdimension of the scale through its application to 74 university students are given in Table 1.

Total reliability coefficient of the scale was found to be 0.74 . If the reliability coefficient is higher than 0.70 , the scale is acceptable (Gliem and Gliem, 2003).

Interview protocol: The researchers developed the interview questions. Questions were prepared separately to compare similar content before and after the course of NOS [Table 2]. Different questions were prepared to prevent familiarity of the participants with the questions. The first question of the pre- and post-interviews reflects students' view about the influence of the NOS on social and cultural values. This question was taken from the VNOS-C scale (Lederman et al., 2002).

Pre-interviews were held before the participants received their education on the nature and NHOS, post interviews were after the participants completed the course.

\begin{tabular}{lc}
\hline Table 1: Values test split-half Cronbach's alpha values \\
\hline Values & $\boldsymbol{n}=\mathbf{7 4}$ \\
\hline Theoretical & 0.75 \\
Economic & 0.75 \\
Esthetic & 0.70 \\
Social & 0.72 \\
Political & 0.71 \\
Religious & 0.81 \\
\hline
\end{tabular}

\section{Data Analysis}

Descriptive statistics of the values of the 28 elementary science teacher candidates in the dimension of conceptualization were analyzed through Spearman's Rho analysis from nonparametric tests since the data were not distributed normally. All participants were enrolled in a lecture including two NOS teaching approaches either (i) direct and reflective or (ii) historical approaches for the semester. The six interviewees were selected among the 28 elementary science teacher candidates according to value scale scores from each level: High, medium, and low. The interviews conducted with teacher candidates were recorded. The recordings were transcribed, and the statements regarding conceptual value dimensions were categorized by two different researchers. The match between the categories created by the researchers was checked, the non-matching statements were discussed, and a consensus was reached. Then, the codes were determined by the researchers for each interview questions in pre- and post-interview data. These codes were collected under the previously categorized conceptual value dimensions. Examples of the value statements used by the science teacher candidates were given and interpreted under these dimensions (Miles et al., 2013). In addition, changes in participants' views of the emphasized NOS aspects were uncovered in three categories namely naïve, informed and no comment.

\section{FINDINGS}

As a result of the Spearman's Rho analysis, the descriptions of values of science teacher candidates in the dimension of conceptualization are presented in Table 3.

The theoretical average for each value is 40 (240 points apportioned among six values), but individual profiles often demonstrate unique value patterns. When values of the teacher candidates in the dimension of conceptualization were examined, it was seen that scores from value scale ranged between 34 and 57 points for theoretical value, between 29 and 52 points for economical values, between 22 and 46 points for esthetic values, between 29 and 50 points for social values, between 32 and 53 points for political values, and between 18 and 45 points for religious values. Moreover, the mean of the theoretical values was the highest and the religious values was the lowest. According to mean scores, 28 elementary science teacher candidates had a greater theoretical value dimension than the religious value dimension.

An analysis of the interviews conducted with teacher candidates revealed the codes of the value orientations and NOS views in the pre- and post-interviews about each value dimension as shown in Table 4.

As seen in Table 4, in the classification of the value orientations of science teacher candidates, participants were seen to be more informed about theoretical, social, and religious values particularly in the post-interview. In addition, a decrease was seen in the informed category of their comments about 


\section{Table 2: Nature of science interview questions (pre-post)}

\section{Question \\ Interview protocol pretest}

1. Theoretical value
Dinosaurs are believed to have existed 65 million years ago. Two of the hypotheses created by the scientists to explain this existence are accepted more by the scientists. One of the hypotheses created group of scientists argues that a huge meteor has hit the world 65 million years ago and caused a series of events that led to extinction. The second hypothesis created by another group of assistants claims that a large and drastic volcanic eruption was responsible for extinction. If the scientists in both groups access the same data and use the same data while drawing these conclusions, how do these different conclusions emerge? (VNOS-C)

2. Religious value

In the middle age, it was believed in the Christian understanding that orbit of the earth was a circle because God has created the universe in the most perfect form and the most perfect geometric form was circle. If you were a Christian, would this understanding influence the way your dimension of perceiving the form of the orbit of the earth?
3. Social value

4. Political value

5. Economic value

6. Esthetic value
The news you read in a newspaper says that the elixir of youth is found. What would you think when you read this news? Why? Would you believe this? What do you need to believe this? Explain with reasons

During the times when the second world war was going to emerge, Müller, a German scientist, and Molly, a Jewish scientist, were conducting a joint scientific research in a science institute located in Germany. However, Molly escaped from Germany due to the second world war and settled in the Netherlands. In the meantime, he continued the scientific researches by interpreting the results found by Müller through corresponding with him. Finally, they achieved the conclusion of their research in the laboratory. Müller sent him the conclusion and this made Molly very happy. However, after a while, Müller published those research conclusions in "Science Journal" with an article he has prepared. But Molly's name was not cited in the study. Do you find this behavior of Müller right? Explain. For what purpose might have Müller committed this behavior? Explain the reasons You want to buy a new dishwasher to your house, and when you go the shop for buying, the seller offers you two dishwashers. One of the dishwashers fits very much to the furniture and color of your kitchen and its outer look is too nice, and the other is ordinary but its washing time is shorter and spends less electricity than the other. In this case, which dishwasher would you like to buy?

If you had a quite lot of monetary resource, would you use it for the restoration of historical works (mosque, bridge, ancient city, etc.), or in a scientific project, or aid to charity organizations such as soup kitchen, child protection institution, etc.?

\section{Interview protocol posttest}

Some people assert that science is influenced by social and cultural values. Namely, science reflects social and political values, philosophical assumptions, and reasonable norms of the culture in which it is produced. Yet, others assert that the science is universal. Namely, science goes beyond national and international borders and is not influenced by social, political, and philosophical values, and reasonable norms of the culture in which it is produced

If you believe that science reflects the social and cultural values, explain why. Support your answer with examples

If you believe that science is universal, explain why. Support your answer with examples. (VNOS-C)

"Religion must be established on positive grounds, and turn its back on metaphysics as well as theology. The principle of the humanity religion is living for others. We can make our living happier without thinking from where we came and to where we go. This happiness takes place through loving each other and living for each other. Love humanity as you love a human and live for humanity." For you, should religion not deal with the subjects like theology and metaphysics as in this statement of Auguste Comte? If you were a scientist, would you accept the views accepted by the majority of the scientists? What would the factors influencing your acceptance be?

Einstein, known for this scientific studies, was regarded an important personality in the world politics after the world war II and received offer for the presidency from Israel. However, Einstein rejected that offer and helped in the establishment of Hebrew University in Jerusalem with Dr. Chaim Weizmann. If you were in the shoes of Einstein, would you prefer the offer or would you want to continue your scientific studies? Why?

You want to buy a house; which influences more your decision about the house you will choose?

The house you will choose is close to the places such as the hospital, school, and shopping center. Interior and exterior design of the house you will choose is beautiful

A technology Institute has assigned a project to Prof. Dr. Wisenheimer and Prof. Dr. Alec Smart. The invention to be made by one of them will be taken into consideration. If you were the director of this institute, which of the following criteria would you place more importance to in evaluating the projects (explain your choice)?

a. Outer look of the product developed

b. It's being solution for a problem

c. What it will bring into the institute the political value dimension. Science teacher candidates' awareness of economical and esthetic values in both pre- and post-interviews was low. Moreover, only two students made interpretations about political values in their post-interview.
When the content of the answers given to the questions was examined, the content of answers given in the post-interview was seen to have increased. If we reviewed the science teacher candidates separately. 


\begin{tabular}{lccccc}
\hline \multicolumn{5}{l}{ Table 3: Descriptive statistics of value preferences of science teacher candidates in the dimension of conceptualization } \\
\hline Values in conceptual dimension & $\boldsymbol{n}$ & Minimum & Maximum & Mean & Standard deviation \\
\hline Theoretical & 28 & 34 & 57 & 49.143 & 5.661 \\
Economic & 28 & 29 & 52 & 41.464 & 5.447 \\
Esthetic & 28 & 22 & 46 & 37.607 & 5.692 \\
Social & 28 & 29 & 50 & 41.393 & 5.538 \\
Political & 28 & 32 & 53 & 30.714 & 5.028 \\
Religious & 28 & 18 & 45 & & 8.290 \\
\hline
\end{tabular}

Table 4: Value orientations of science teacher candidates in the pre- and post-interviews

\begin{tabular}{|c|c|c|c|c|c|c|c|c|c|c|c|c|}
\hline \multirow{2}{*}{$\begin{array}{l}\text { Student } \\
\text { name }\end{array}$} & \multicolumn{6}{|c|}{ Pre-interview } & \multicolumn{6}{|c|}{ Post-interview } \\
\hline & Theoretical & Economic & Esthetic & Social & Political & Religious & Theoretical & Economic & Esthetic & Social & Political & Religious \\
\hline Gamze & - & 0 & 0 & - & - & + & + & + & + & + & 0 & + \\
\hline Aleyna & - & - & 0 & + & - & - & + & + & + & + & 0 & + \\
\hline Ayla & + & 0 & - & - & - & 0 & + & 0 & 0 & + & 0 & + \\
\hline Selim & - & 0 & - & + & - & + & + & 0 & 0 & + & + & + \\
\hline Arda & - & - & - & + & - & - & + & - & - & + & - & + \\
\hline Meryem & - & 0 & 0 & + & - & - & + & 0 & 0 & + & 0 & + \\
\hline
\end{tabular}

“_" represents naïve view, "+" represents informed view, and " 0 ” represents no comment

Theoretical values: Considering the results of interview questions about theoretical values and NOS views about socially and culturally embeddedness of science and subjectivity of science, science teacher candidates' NOS views were improved after the HNOS instruction. The codes of preinterviews about theoretical values were certainty, universal, personal experiences, and scientific method. Participants gave more answers on the post-interview than on the pre-interview about theoretical values. The codes of post-interviews about theoretical values were tentativeness, influence of social and cultural values, subjectivity, empirical based, and benefits of society. Participants made more comments about theoretical values and NOS views about influence of social and cultural values on the NOS after the HNOS instruction. For example, one of the participants, Gamze, stated "there is no certainty in science; these may be disproved, so that even theory can change at this time." Her answer to the question about the influence of social and cultural values on the NOS in her pre-interview shows that she does not have awareness of influence of social values on science. Then, Gamze's statements "it varies depending on the status of the country he lives in. Science should be apart from belief. Science is certainly universal. I would prove it myself and see with my own eyes, " in her post-interview showed that her awareness of social value dimension had grown. Moreover, her statement claimed that she was required to prove the scientific knowledge herself to believe it. This claim demonstrated her awareness of the theoretical value. In her pre-interview, another participant, Aleyna, expressed her views on the NOS "their thoughts are clear. They consider proving it in the framework of their thoughts, to prove their fields... If it is proved and experimented, if its accuracy is validated, I would accept it. "She was aware that science can change "not universal. Something that can change is not certain. It is influenced by social and cultural values. I would accept it if I compare what I have done with what has been previously done and achieved the same conclusions" in her post-interview. Moreover, she put the theoretical value at the forefront stating that she would not accept the scientific knowledge without it being experimented and proved. Another interviewed participant, Meryem, with regard to the theoretical value, stated "It shall be published scientifically. To do this, for instance, it should be applied to more people." This statement showed her awareness of the theoretical value in the pre-interview. However, her awareness of the theoretical value increased in her post-interview:

I would not accept. I would research, too. I would apply the same steps of that experiment, but I would accept it so... the one that washes in the shorter time and spends less electricity. For energy saving. For the world's resources not to deplete.

Similarly, Selim was aware of the theoretical value as indicated in his pre- and post-interviews. However, his theoretical value awareness became more apparent in the post-interviews:

Findings obtained in consequence of logical values are evaluated through a certain systematic. They are accepted through the perspectives drawn by science... I consider the house's closeness to the places such as a hospital, school, etc... I would consider the benefit of the society. Because I believe the more it benefits the society, the more useful it is.

Economic values: The results of interview questions about economic values showed that these science teacher candidates did not significantly improve as only two participants were seen as informed about the economic value after the HNOS instruction. In the pre-interviews, the codes were personal benefit and energy saving. These codes indicate that participants behaved for personal benefits. In post-interviews, the codes were social benefit and esthetics needs. These codes 
indicate that participants now behaved for social benefits. For example, Gamze did not address the economic value at all in her pre-interview. Whereas she put the economic value at the forefront, then addressed the social value with her statement "I would consider what the product brings into the institute. Since I am interested in this field, I would then consider its benefit to the society" in the post-interview. Likewise, Aleyna put the economic and social values in the forefront with her statement "I would consider the latter. Because I would provide saving both from energy resources and materially... I would aid to soup kitchen and child protection institution" in her pre-interview. She put the esthetic and social value at the forefront and pushed the economic value into the background with her post-interview statement "I would consider interior and exterior design beauty and usefulness of the house I will choose. I would consider the benefit of the society. Then I would consider what it brings into the institute. Others may be postponed."

Esthetic values: The results of interview questions about esthetic values showed that these science teacher candidates did not greatly improve as there was an equal number of codes about esthetic value before and after the HNOS instruction. While Ayla, Selim, and Arda talked about esthetic values before the course instruction, Gamze, Aleyna, and Arda talked about esthetic values after the instruction. Some codes from the pre-interviews and these codes were creativity, energy-saving behaviors, and social institution. In the postinterviews, codes were interior and exterior design beauty, usefulness, and social benefits. Considering codes from the pre- and post-interviews, participants did not indicate any esthetic values and views about the NOS aspects before the HNOS instruction, but they cared about esthetic values such as designs of constructions and scientific projects for social benefits. In her pre-interview, Ayla showed awareness of esthetic value with her statement "People's imaginations may be the differences in their observations. Their creativity may be different." Another participant Aleyna put the economic and social values at the forefront instead of esthetic values with her pre-interview statement "I would consider the latter. Because I would provide saving both from energy resources and materially... I would aid to soup kitchen and child protection institution." She then put the esthetic and social value at the forefront with post-interview statement "I would consider interior and exterior design beauty and usefulness of the house I will choose. I would consider the benefit of the society. Then I would consider what it brings into the institute. Others may be postponed."

Social values: The results of interview questions about social values showed that these science teacher candidates did slightly improve their social values. In the pre-interview, participants stated the codes of energy-saving behavior for their family and social benefits for own beliefs. In the post-interview, participants stated the codes of energy saving behavior for social benefits, social and cultural influence on scientific knowledge, logic, religious belief, work for social benefits, child protection institution, and helping people. Science teacher candidates gave more importance to the benefits of all people and social values in their post-interviews. Gamze put at the forefront the theoretical and social value using her statement "I would want the one that spends less electricity. I would want to contribute to global warming," in her pre-interview and the theoretical and social value using the statement "it is important that the house I will choose is close to the places such as a hospital, school, shopping center, etc. It is more important for my child and my family."

Aleyna put the social value at the forefront with her postinterview statement "taking part in foundation of the university is more important, I would be useful to people." Some of participants believed that NOS was influenced by social and cultural values. Furthermore, they emphasized the effect of political and religious beliefs of the society on scientific knowledge.

Ayla used the statement "Society might not accept the universal things found by several scientists due to their beliefs. There may be religious beliefs... Religion should not deal with metaphysics. Metaphysics and religion are interrelated," in her post-interview. This statement showed her awareness of the influence of social and religious values.

Selim did not indicate awareness in the pre-interview with regard to the influence of social values on scientific knowledge, whereas he expressed that it would be influenced by religious, social, and political values in the post-interview. For instance, his statements "It is influenced by social and cultural values. Like Christian world's grounding on the book of God when he told that the earth was round. I would believe. If God says, it is true... Because there is no logic in religion, logic exists in the entire science" showed his awareness of social and religious values.

Arda used more statements in the post-interview particularly about social value. In the pre- and post-interviews, he stated that NOS was influenced by social and cultural values. He used only one statement with regard to social value in the pre-interview. This statement "I would use the money I possess for benefit of the society. According to my own values of belief, I believe that I must do this, that this is truer" showed the perception of Arda about social value. In the post-interview, his statements:

I would prefer scientific studies. I would want this because doing this is for the benefit of the people. I would not want to work in a field where I could not provide benefit to the society... I would give it to child protection institution. People are more important for me. What matters is helping people showed the increase in his awareness of social value.

With regard to the influence of social and cultural values on NOS, Meryem was seen to have awareness in both pre- and post-interviews. Her awareness of the influence of social and cultural values on science is ascertained with her statement "It might be resulting from social environments of the scientists. 
Their raising style, the society they live in, their religious beliefs may be different" in her pre-interview and "Science is not universal. Evolution is not accepted since Turkey because our country is a Muslim country. It is not universal due to the reasons deriving from the people today" in the post-interview.

Political values: The findings of this study showed that these participants turned to scientific values rather than political values in the post-interview. While the codes about political value from the pre-interview data were power, being president, all my benefits, racism, and politics, the codes of about political value from the post-interview data were science, happy, and scientific knowledge. With regard to the political value, Gamze used the statement "Because the German are racists and they do not like the Jewish at all" in the pre-interview, whereas she used the statement "I would not be interested in politics; I would be interested in science, which makes me happy and which is my world" in the post-interview. This answer showed us that while she placed more importance on political value in the pre-interview, she tended toward esthetic and theoretical value in the post-interview. With regard to political value, "she did not make any comment about political value in the postinterview." While Aleyna put the political value at the forefront with the statement "... for own benefit" in the pre-interview. Selim stated that the power and selfishness concepts were incorporated in the political value with his statement "Yes, I would be state president. Because I would rule everyone."

Religious values: The findings of interviews about religious values indicated that participants' views were not improved enough about the effect of religious and cultural values on scientific knowledge. The codes were acquired from the pre-interviews, such as hindering of scientific progress, stimulating inquiry, creativity and imagination, different beliefs for everyone, and unchangeable. The codes about religious value in the post-interviews were religion inside of the human, different religions for everyone, science related with religion, social rejection of scientific knowledge, religious beliefs, interrelationship between religion and metaphysics, effect of beliefs on scientists' point of view, self-experience, and tentative. After the HNOS instruction, they were aware of tentativeness, empirically-based, socially, and culturally embeddedness of the NOS aspects. With regard to the religious value, Gamze stated "I would believe what is written in the Koran and Bible. But I would believe such that those people do not hinder my advancement." She put the religious value at the forefront in the pre-interview. In the post-interview, she expressed that, besides religious values, theoretical values were important "Religion should not be involved. Religion is something that is inside the human. There are a lot of religions in the world, it differs for everyone."

With regard to the religious values, Aleyna put the theoretical value at the forefront and expressed that religion was important "I would expect him to prove somehow. Of course, religion would raise a question mark in my mind but I would inquire" in the pre-interview. In the post-interview, she emphasized the religion more with her statement “... should be in the relationship with religion."

Ayla expressed that the differences in scientific knowledge stemmed only from creativity and imagination in the pre-interview and added the influence of religious beliefs and society in the post-interview. For instance, Ayla stated "Society might not accept the universal things found by several scientists due to their beliefs. There may be religious beliefs... Religion should not deal with metaphysics. Metaphysics and religion are interrelated" in the post-interview. This statement showed her awareness of the influence of social and religious values.

Arda used the statement "beliefs of the scientists may be different" in the pre-interview, whereas he used the statement "Social, cultural values may be different. They may be viewing the event partially. " in the post-interview. While he told that he would believe scientific knowledge with the statement "I would believe if it has been experimented on people" in the pre-interview, he stated that he would believe if he proved it himself in the postinterview "I would try to experiment it myself... I would try to achieve the correct result by experiment the study many times."

With regard to the religious value, Meryem was seen to think that religion and science should be distinct with her statement "For a topic like evolution, religion and science should be distinct from each other. Religion is a phenomenon that comes with the book and that cannot be developed. They should be distinct for the science to develop" in the post-interview.

\section{DISCUSSION AND CONCLUSION}

After the teacher candidates received their education on the nature and NHOS, there was an increased awareness about conceptual values and an informed view about the NOS aspects. The science teacher candidates examined lives of prominent scientists, learning about the experiences gained by the scientist, and becoming aware of the dimensions of the NOS. Within the scope of the education of the nature and NHOS, this may be the cause of the change in their awareness of conceptual values. In addition, participants were informed about the cultural and social influence on science, tentativeness, subjectivity, and empirical basis of science by learning more of the historical development of scientific knowledge. One rationale for teaching the NOS was learning about NOS which would promote conscious decisions on scientifically based societal and personal issues in this study. The findings from the interviews showed that participants used their understanding of the NOS when making decisions on scientifically based societal and personal issues. These participants placed cultural and social effect on scientific knowledge, tentativeness, subjective, and empirical basis of science in their post-instruction interviews. The influence of understanding of the NOS and conceptual values on decisionmaking process about scientifically based societal and personal issues was probably the most significant finding of this study. In parallel with these findings, Bell and Lederman (2003) found that teachers used personal values, morals/ethics, and social 
concerns when making decisions. However, Bell and Lederman (2003) found that the teachers did not use understanding of the NOS when making decisions about scientifically based societal and personal issues.

As expected, science teacher candidates' mean values about theoretical values were observed to be high. Considering the correlations between the value orientations, there was a significant correlation between the political and religious value. The limitation of this study was that only 28 teacher candidates participated in this study. However, according to Bulut (2010), there was often a strict and complex correlation between religion and politics. Religious beliefs might influence the laws and legitimate the political order. Religion played an effective role in taking political decisions as well as influencing many aspects of the life. In this context, the correlation between religious values and political values of the teacher candidates was an expected result.

In the post-interviews conducted with the science teacher candidates, it was observed that science teacher candidates held more informed views about the NOS, improved theoretical and religious values. In addition, participation in the HNOS course had only minimal influence on these students' economic, esthetic, social, and political values. It was thought that the teacher candidates were concentrating on experiment and observation for proving scientific knowledge since their undergraduate education in science education may have led to the high level of their theoretical values. They addressed both religious and theoretical values during the NOS instruction. In the instruction of the HNOS, the teacher candidates recognized the influence of religion on science in the examination of the development of science in Islamic period and after a recession of science in Europe particular in the "middle age." Another remarkable result is that, with regard to the political and theoretical values, science teacher candidates showed naïve political and theoretical values in their pre-interviews, but they showed informed political and theoretical values in their post-interviews. This may be the result of the course's content concerning the influence of political values of society and culture on theoretical values in the historical development of science. Findings of interview questions indicated that participants gave more informed answers about theoretical, social, and religious values and some NOS aspects after instruction. These NOS aspects were social and cultural influence on science, tentativeness, subjectivity, and empirical basis of science. In parallel to these findings, Driver, Leach et al. (1996) stated that understanding the NOS was necessary for informed decision-making on socioscientific issues and to make sense of science. They suggested that understanding the NOS helped develop an understanding of the values and norms of the scientific community that embody moral commitments that are of general value to society.

HNOS instruction aimed to teach the working of scientific efforts in the NHOS and the social and cultural effects in the development of scientific knowledge to help learners acquire a better understanding of the NOS. In HNOS instruction, it was expected that participants would replace scientists and look at scientific and social events more like them. By this way, participants would better acquire a scientific point of view, an understanding of the NOS and conceptual values. For example, participants highlighted social and cultural influence on acceptance of evolution when they answering interview questions about theoretical, religious, and social values in current study. However, they did not show informed views about economic, esthetic, and political values and some NOS aspects. As a result, participants did not associated science knowledge with NOS aspects and notice common aspects between historical events and current scientific practices (Abd-El-Khalick and Lederman, 2000).

The following recommendations were developed based on the results derived from this study.

The education of the nature and NHOS influences awareness of teacher candidates regarding values. Hence, awareness of values may be further increased by arranging the content of the education considering values and presenting case studies that incorporate each value. A more thorough study should be conducted on a bigger cohort with not only interviews but also observations conducted during lectures to investigate the influence of the nature and NHOS courses on value perceptions of elementary science teacher candidates in conceptual dimension.

As stated in the literature, value orientations of teacher candidates are influenced by their previous learning experiences (Guild, 2001). In addition, within the context of this study, it was seen that the teacher candidates were influenced by their education. For this reason, it is suggested that the effect of the NOS teaching approach on the value orientations of the teacher candidates is examined by other variables related to the education, cultural differences, and individual differences.

In addition, it is suggested to examine the effect of religious values on political values or vice versa within the context of the NOS teaching.

Culture has an important influence on the value orientations of individuals (Schwartz, 2006). For this reason, it is recommended to evaluate the effect of students' cultural diversity on the value orientation. As the current study shows the effect on the answers that students have concerning cultural differences, it is recommended to examine this in future studies. In addition, it was suggested that religious beliefs and beliefs related to scientific knowledge may be related to value orientations.

Finally, it is suggested to study the effect of the indirect approach, the direct and reflective approach, and the historical approach of the NOS lessons on teacher candidates' value orientations. It is thought that different approaches to the NOS teaching will affect the value orientations of teacher candidates differently. It is thought that teacher candidates taking historical approach will be influenced by their value orientations from the negative competition between science and religion in the historical process. 


\section{REFERENCES}

Aavik, T., \& Allik, J. (2002). The structure of Estonian personal values: A lexical approach. European Journal of Personality, 16, 221-235.

Abd-El-Khalick, F., \& Lederman, N.G. (2000). The influence of history of science courses on students' views of nature of science. Journal of Research in Science Teaching, 37, 1057-1095.

Allchin, D. (1998). Values in science and in science education. In: Fraser, B.J., \& Tobin, K.G., (Eds.), International Handbook of Science Education. $2^{\text {nd }}$ ed. Dordrecht: Kluwer Academic Publishers. pp. 1083-1092.

Allchin, D. (1999), Values in science: An educational perspective. Science and Education, 8(1), 1-12.

Allport, G.W., Vernon, P.E., \& Lindzey, G. (1960a). Manual: Study of values. İn: Robinson, J.P., Shaver, P., \& Wrightsman, L., (Eds.), Measures of Personality and Social Psychological Attitudes. New York: Academic Press. pp. 670-673.

Allport, G.W., Vernon, P.E., \& Lindzey, G. (1960b). Test Booklet: Study of Values. Boston: Houghton Mifflin Company.

Allport, G.W. (1960). Personality and Social Encounter. Boston: Beacon Press.

Allport, G.W. (1961). Pattern and Growth in Personality. New York: Holt, Rinehart \& Winston.

Akerson, V.L., \& Abd-El-Khalick, F.S. (2005). "How should I know what scientists do?-I am just a kid": Fourth-grade students' conceptions of nature of science. Journal of Elemantary Science Education, 17(1), 1-11.

Ardac, D., Albayrak-Kaymak, D., \& Erktin, E. (1994). Social and political attitudes of Turkish youth: A bridge or a gap between east and west? Medicine and Mind, 9(2), 39-57.

Braithwaite, V.A., \& Scott, W.A. (1991). Values. In: Robinson, J.P., Shaver, P., \& Wrightsman, L., (Eds.), Measures of Personality and Social Psychological Attitudes. New York: Academic Press. pp. 661-753.

Bulut, M. (2010). Öğrencilerin dini inançları ve kimlikleri ile siyasal tercihlerinin ilișkisi. Ankara Üniversitesi Dil ve Tarih Coğrafya Fakültesi Antropoloji Dergisi, 24, 115-132.

Gliem, J.A., \& Gliem, R.R. (2003). Calculating, Interpreting, and Reporting Cronbach's Alpha Reliability Coefficient for Likert-type Scales. Midwest Research-to-Practice Conference in Adult, Continuing, and Community Education.

Guild, P.B. (2001). Diversity, learning style and culture. New Horizons for Learning. Available from: http://archive.education.jhu.edu/PD/ newhorizons/strategies/topics/Learning\%20Styles/diversity.html.

Koruklu, N., \& Aktamış, H. (2012). Öğretmen adaylarının kavramsallaştırma boyutundaki değer tercihlerinin incelenmesi. Kuram ve Uygulamada Ĕgitim Bilimleri Dergisi Değerler Ĕgitimi Sempozyumu Ek Özel Sayısı, 12(2), 1303-1307.

Lederman, N.G. (2003). What works: A commentary on the nature of scientific research. Contemporary Issues in Technology and Teacher Education, 3(1), 1-8.

Lederman, N.G., Abd-El-Khalick, F., Bell, R.L., \& Schwartz, R.S. (2002).
Views of nature of science questionnaire (VNOS): Toward valid and meaningful assessment of learners' conceptions of nature of science. Journal of Research in Science Teaching, 39, 497-521.

Lederman, N.G., Lederman, J.S., \& Antink, A. (2013). Nature of science and scientific inquiry as contexts for the learning of science and achievement of scientific literacy. International Journal of Education in Mathematics, Science and Technology, 1(3), 138-147.

Levinson, R., \& Turner, S. (2001). Valuable Lessons: Engaging with the Social Context of Science in Schools. London: The Wellcome Trust

McComas, W.F., Clough, M.P., \& Almazroa, H. (1998). The role and character of the nature of science in science education. In: McComas, W.F., (Ed.), The Nature of Science in Science Education: Rationales and Strategies. Boston: Kluwer Academic Publishers. pp. 3-39.

Milli Eğitim Bakanlığı (MEB). (2017). Fen Bilimleri Dersi (İlkokul ve Ortaokul 3, 4, 5, 6, 7 ve 8. Sinıflar) Öğretim Programı. Ankara: Milli Eğitim Bakanlığı Talim ve Terbiye Kurulu Başkanlığı.

Miles, M.B., Huberman, A.M., \& Saldana, J. (2013). Fundamentals of qualitative data analysis. Qualitative Data Analysis: A Methods Sourcebook. $3^{\text {th }}$ ed.). Los Angeles: Sage Publication.

Muğaloğlu, E.Z., \& Bayram, H. (2010). A structural model of prospective science teachers' nature of science views. Scandinavian Journal of Educational Research, 54(6), 597-614.

National Research Council (NRC). (2012). A Framework for K-12 Science Eduation: Practices, Crosscutting Concepts, and Core İdeas. Washington, DC: The National Academy Press.

Ratcliffe, M. (2012). Science literacy and scientific values: İmplications for formal education. Rendiconti lincei. Science Fisiche $e$ Naturali, 23, 35-38

Robinson, J.P., Shaver, P.R., \& Wrightsman, L.S., (Eds.). (2013). Measures of Personality and Social Psychological Attitudes: Measures of Social Psychological Attitudes. Vol. 1. San Diego, CA: Academic Press.

Roy, A. (2003). Factor Analysis and Initial Validation of the Personal Values Inventory. Unpublished Doctorate Dissertation, USA: Tennessee State University.

Sadler, T.D., Amirshokoohi, A., Kazempour, M., \& Allspaw, K.M. (2006). Socioscience and ethics in science classrooms: Teacher perspectives and strategies. Journal of Research in Science Teaching, 43(4), 353-376.

Sarı, E. (2005). Öğretmen adaylarının değer tercihleri: Giresun eğitim fakültesi örneği. Değerler Eğitimi Dergisi, 3(10), 73-88.

Scheler, M. (1913-1916/1973). Formalism in Ethics and Non-formal Ethics of Values. Evanston, IL: Northwestern University Press. Translated from German by Frings, M.S., \& Funk, R.L.

Schwartz, S.H. (2006). A theory of cultural value orientations: Explication and applications. Comparative sociology, 5(2), 137-182.

Solomon, J., Duveen, J., Scot, L., \& Mccarthy, S. (1992). Teaching about the nature of science through history: Action research in the classroom. Journal of Research in Science Teaching, 29(4), 409-421.

Stein, H.F. (1985). Therapist and family values in a cultural context Counseling and Values, 30, 35-45. 